\title{
APPLICATION OF QUEUING THEORY TO A FAST FOOD OUTFIT: A STUDY OF BLUE MEADOWS RESTAURANT
}

Seigha Gumus

Department of Research, Collaboration and Consultancy South-South Office, National Centre for Technology Management Niger Delta University, Nigeria E-mail: seighagumus@gmail.com

Gordon Monday Bubou Department of Research, Collaboration and Consultancy South-South Office, National Centre for Technology Management Niger Delta University, Nigeria

E-mail: gbubou@gmail.com

Mobolaji Humphrey Oladeinde Production Engineering Department Faculty of Engineering University of Benin, Nigeria E-mail: moladeinde@uniben.edu.ng

Submission: $28 / 11 / 2016$

Revision: 16/12/2016 Accept: 25/12/2016

\section{ABSTRACT}

The study evaluated the queuing system in Blue Meadows restaurant with a view to determining its operating characteristics and to improve customers' satisfaction during waiting time using the lens of queuing theory. Data was obtained from a fast food restaurant in the University of Benin. The data collected was tested to show if it follows a Poisson and exponential distribution of arrival and service rate using chi square goodness of fit. A 95\% confidence interval level was used to show the range of customers that come into the system within a time frame of one hour and the range of customers served within that time frame. Using the $\mathrm{M} / \mathrm{M} / \mathrm{s}$ model, the arrival rate, service rate, utilization rate, waiting time in the queue and the probability of customers likely balking from the restaurant was derived. The arrival rate $(\lambda)$ at Blue Meadows restaurant was about 40 customers per hour, while the service rate was about 22 customers per hour per server. 
INDEPENDENT JOURNAL OF MANAGEMENT \& PRODUCTION (IJM\&P)

http://www.ijmp.jor.br

v. 8, n. 2, April - June 2017

ISSN: 2236-269X

DOI: 10.14807/ijmp.v8i2.576

The number of servers present in the system was two. The average number of customers in the system in an hour window was 40 customers with a utilization rate of 0.909. The paper concludes with a discussion on the benefits of performing queuing analysis to a restaurant.

Keywords: queuing theory; Poisson distribution; service rate; customer satisfaction; fast food outfit; Blue Meadows Restaurant

\section{INTRODUCTION}

Queuing theory also known as Random System Theory is the body of knowledge about waiting lines and is now an entire discipline within the field of operations research (NOSEK; WILSON, 2001; KAVITHA; PALANIAMMAL, 2014; RAMAKRISHNA; MOHAMEDHUSIEN, 2015).

In fact, queuing theory has become a valuable tool for operations managers (RAMAKRISHNA; MOHAMEDHUSIEN, 2015). The authors maintain that waiting has become part of everyday life. For example, queuing system has been employed in our day to day commercial (as well as socio-political) lives (KAVITHA; PALANIAMMAL, 2014).

Some scholars maintain that we queue or wait in line to get served in commercial outfits like checkout counters, banks, super markets, fast food restaurants etc. (KAVITHA; PALANIAMMAL, 2014), grocery stores, post offices, to waiting on hold for an operator to pick up telephone calls, waiting at an amusement park to go on the newest ride (MANDIA, 2009). Others according to the authors include: waiting in lines at the movies, campus dining rooms, the registrar's office for class registration, at the Division of Motor Vehicles etc. We equally queue in other socio-political settings like queuing to vote, waiting in line to be attended to by a public servant in government offices, etc.

Waiting causes not only inconvenience, but also frustrate people's daily lives. Thus, unmanaged queues are detrimental to the gainful operation of service systems and results in a lot of other managerial problems (YAKUBU; NAJIM, 2011).

In order to reduce the frustrations of customers, managers adopt certain measures like multiple line/multiple checkout systems (RAMAKRISHNA; MOHAMEDHUSIEN, 2015). The duo further stated that, in recent years, many 
INDEPENDENT JOURNAL OF MANAGEMENT \& PRODUCTION (IJM\&P)

http://www.ijmp.jor.br

v. 8, n. 2, April - June 2017

ISSN: 2236-269X

DOI: $10.14807 /$ ijmp.v8i2.576

banks, credit unions, as well as fast food providers have shifted to a queuing system whereby customers wait for the next available cashier, as this removes the frustrations of "getting in a slow line" since one slow transaction does not affect the throughput of the remaining customers.

Queuing theory according to Dharmawirya and Adi (2011) was particularly suitable to be applied in a fast food or restaurant settings, since it has an associated queue or waiting line where customers who cannot be served immediately have to queue for service. Blue Meadows is a fast food restaurant selling fast food cuisines with a minimal table service for its customers.

Blue Meadows restaurant is situated in the University of Benin, behind the Postgraduate School. This fast food restaurant operates in a manner that customers can take away their orders immediately after payment or sit down at the premises to enjoy their meal. However, clients suffer unnecessary delays, especially during peak periods. This shows a need of a numerical model for Blue Meadows' management to understand the situation better.

Thus, the aim of the study was to assist Blue Meadows solve this problem by decreasing customers' waiting time by modeling a queuing theory to simulate the waiting lines. It is intended to show that queuing theory satisfies the model when tested with a real - case scenario.

The remainder of the paper is structured as follows: the next section provides a background into queuing theory, its associated terminology, its applications and its relationship to customer satisfaction, as well as a review of related works. Next, we discuss the Blue Meadows' Model. This is followed by the presentation of analysis and results. The results are then discussed, and of course we conclude with a summary.

\section{THEORETICAL BACKGROUND}

The queuing theory is known as Random System Theory which has the solutions for statistical interference and problem of behavior and optimization in queuing system (KAVITHA; PALANIAMMAL, 2014). It is the formal study of waiting lines which has now become an area of scientific inquiry, sub-discipline within operations research (COPE et al., 2011). 
INDEPENDENT JOURNAL OF MANAGEMENT \& PRODUCTION (IJM\&P)

http://www.ijmp.jor.br

v. 8, n. 2, April - June 2017

ISSN: 2236-269X

DOI: 10.14807/ijmp.v8i2.576

The origin of queuing theory dates back over a century. Indeed, Chowdhurry (2013) confirms that the study of waiting lines was one of the oldest and most widely employed quantitative analysis techniques. However, Johannsen's "Waiting Times and Number of Calls" (an article published in 1907 and reprinted in Post Office Electrical Engineers Journal, London, October, 1910) seems to be the first paper on the subject.

It had its early research work in the early 1900 s by a Danish engineer named A.K Erlang of the Copenhagen Telephone Company (COOPER, 1990; COPE et al. 2011; CHOWDHURRY, 2013; RAMAKRISHNA; MOHAMEDHUSIEN, 2015). Erlang is claimed to have derived several important formulas for teletraffic engineering that today bore his name.

According to Ramakrishna and Mohamedhusien (2015), it was only after World War II that works on waiting line models were extended to other kinds of problems. The authors maintain that, today a wide variety of seemingly diverse problem situations are recognized as being described by the general waiting line model.

Indeed, queuing theory has many applications in human endeavors, some of which include: telephony; manufacturing; inventories; dams; supermarkets; computer and information communication systems and networks; call centers; hospitals, banking, etc. (SZTRIK, 2010). Nosek and Wilson (2001) confirm that queuing theory has been used extensively by the service industries.

Undoubtedly, there are numerous factors that affect a customer's perception of the waiting experience, some of which include: physical, psychological and emotional. If there were to be no queue at all, it would create the impression that the value of the attraction is to some extent diminished. However, one may observe that attractions with short queues tend to attract less public. So, in principle, it is important not to aim at eliminating queues, but instead concentrate on giving people an option to join the queue, or skip part of the queue and spend the time somewhere else.

The dynamics of queues have been analyzed by using steady-state mathematics. Essentially, it is purely a mathematical approach that is employed in the waiting line analysis (KAVITHA; PALANIAMMAL, 2014). While various models 
constitute several queuing systems (KAVITHA; PALANIAMMAL, 2014), such queuing processes are described by using the Kendall-Lee (1953) notation which uses mnemonic characters that specify the queuing system:

\section{$\mathrm{A} / \mathrm{B} / \mathrm{C} / \mathrm{D} / \mathrm{E} / \mathrm{F}$}

- A: Specifies the nature of the arrival process.

- B: Specifies the nature of the service times.

- C: Specifies the number of parallel servers

- D: Specifies the queue discipline.

- E: Specifies the maximum number of entities in the system.

- F: Specifies the size of the population from which entities are drawn.

\subsection{Characteristics of a queuing process}

The queuing theory considers mainly six general characteristics of any queuing processes:

i. Arrival pattern of customers: inter-arrival times most commonly fall into one of the following distribution patterns: A Poisson distribution, a Deterministic distribution, or a General distribution. However, inter-arrival times are most often assumed to be independent and memoryless, which is the attributes of a Poisson distribution.

ii. Service pattern: the service time distribution can be constant, exponential, hyper exponential, hypo-exponential or general. The service time is independent of the inter-arrival time

iii. Number of servers: the queuing calculations change depends on whether there is a single server or multiple servers for the queue. A single server queue has one server for the queue. This is the situation normally found in a grocery store where there is a line for each cashier. A multiple server queue corresponds to the situation in a bank in which a single line waits for the first of several tellers to become available.

iv. Queue Lengths: the queue in a system can be modeled as having infinite or finite queue length. 
INDEPENDENT JOURNAL OF MANAGEMENT \& PRODUCTION (IJM\&P)

http://www.ijmp.jor.br

v. 8, n. 2, April - June 2017

ISSN: 2236-269X

DOI: 10.14807/ijmp.v8i2.576

v. System capacity: the maximum number of customers in a system can be from 1 up to infinity. This includes the customers waiting in the queue.

vi. Queuing discipline: there are several possibilities in terms of the sequence of customers to be served.

- FCFS: First Come, First Served. This is the most commonly used discipline applied in the real-world situations, such as check-in counters at the airport.

- LCFS: Last Come, First Served. This illustrates a reverse order service given to customer versus their arrival.

- SIRO: Service in Random Order.

- PD: Priority Discipline. Under this discipline, customers will be classified into categories of different priorities.

According to Nosek and Wilson (2001), queuing management has been applied very successfully in several service-oriented industries. For instance, many researchers have previously used queuing theory to model the fast food operation, and many service industries to reduce cycle time in a busy system such as hospitals and restaurants as well as to increase throughput and efficiency (see for example, SOMANI; DANIELS; JERMSTAD, 1982; PIERCE (II); ROGERS; SHARP, 1990; ANDREWS; KHARWAL, 1991; PARSONS, 1993; JONES; DENT, 1994; PROCTOR, 1994; ROSENFELD, 1997; BRANN; KULICK, 2002; CURIN; VOSKO; CHAN; TSIMHONI, 2005; TYAGI; SAROA.; SINGH, 2014; OLADEJO; AGASHUA; TAMBER, 2015).

Nevertheless, the type of queuing system a business uses is an important factor in determining how efficient the business is run (ZHANG; NG; TAY, 2000). However, there are several other determining factors for a restaurant to be considered a good or a bad one; taste, cleanliness, the restaurant layout and settings are some of the most important factors.

These factors when managed carefully will be able to attract plenty of customers. Besides attributes such as location, ambience and quality of food (AUTY, 1992), other important factors to be considered is when a restaurant has succeeded in attracting customers is the price and the customers queuing time (DHARMAWIRYA; ADI, 2011; LI; LEE, 1994). 


\section{BLUE MEADOWS' QUEUING MODEL}

The method employed in the data collection was by observation. The data collected was the arrival time, inter-arrival time, waiting time and number of customers in the queue at Blue Meadows restaurant for a period of five days (Monday - Friday) with a time frame of one-hour window intervals from 09Hrs $15 \mathrm{Hrs}$ daily. Based on observation, it is concluded that the model that best illustrates the operation of Blue Meadows is M/M/2.

This means that the arrival and service time are exponentially distributed (Poisson Process). The restaurant system consists of only two servers. However, the data obtained has been tested to show that it fits both Poisson and exponential distribution. However, $\chi^{2}$ distribution is used for testing the goodness of fit for the set of data collected. The actual frequencies are compared to the frequencies that theoretically would be expected to occur if the data follows the Poisson distribution.

Assume a random variable T represents either inter-arrival or service times.

The random variable is said to have an exponential distributed with parameter $\mu$, if its probability density function is:

$$
f_{T}(t)=\left\{\begin{array}{lll}
\mu \square^{\mu t} & \text { for } t \geq 0 \\
0 & \text { for } t<0
\end{array}\right.
$$

The cumulative probabilities are:

$$
\begin{aligned}
& p\{T \leq t\}=1-\square^{-\mu t} \\
& p\{T>t\}=\square^{-\mu t} \quad(t \geq 0)
\end{aligned}
$$

The expected value and variance of $T$ are, respectively,

$$
\begin{aligned}
& E(T)=\frac{1}{\mu} \\
& \operatorname{Var}(T)=\frac{1}{\mu^{2}}
\end{aligned}
$$


The confidence intervals for average service rate and average arrival rate can be estimated. Assuming service time and arrival time are identically independent with $\mathrm{N}(0,1)$ then the $95 \%$ confidence interval for arrival can be:

$\left[(\text { mean arrival time }+1.96 * \mathrm{SE} \text { (mean arrival time) })^{-1}\right.$, (mean arrival time $-1.96 \star \mathrm{SE}$ (mean arrival time) $\left.)^{-1}\right]$

Where $\mathrm{SE}($ mean arrival time $)=\mathrm{SD}($ mean arrival time $) / \mathrm{n}$

Similarly, 95\% confidence interval for service rate can be:

$[(\text { mean service time }+1.96 \star \mathrm{SE} \text { (mean service time })]^{-1}$,

The following queuing parameters are used to describe the model.

Utilization factor, $\rho=\frac{\lambda}{s \mu}$

The probability that the system shall be idle,

$=\left[\sum_{n=0}^{s-1} \frac{1}{n !}\left(\frac{\lambda}{\mu}\right)^{n}+\frac{1}{s !}\left(\frac{\lambda}{\mu}\right)^{s} \frac{s \mu}{s \mu-\lambda}\right]^{-1}$

The expected number of customers waiting in the queue,

$$
=\left[\frac{1}{(s-1) !}\left(\frac{\lambda}{\mu}\right)^{s} \frac{\lambda \mu}{(s \mu-\lambda)^{2}}\right] P_{0}
$$

The expected number of customers in the system,

$$
L_{s}=L_{q}+\frac{\lambda}{\mu}
$$

The expected waiting time of customers in the queue,

$=\frac{L_{q}}{\lambda}$

The expected waiting time a customer spends in the system,

$$
=\frac{L_{q}}{\lambda}+\frac{1}{\mu}
$$


ISSN: 2236-269X

DOI: 10.14807/ijmp.v8i2.576

\section{ANALYSIS AND RESULTS}

To calculate for a 95\% confidence interval for both service time and arrival time, the following were obtained. The standard deviation and mean arrival time is obtained from the data using spread sheet.

Table 1: Confidence intervals for Arrival Rate and Service Rate

\begin{tabular}{|l|l|l|l|l|l|l|l|l|l|}
\hline Days & SD & \multicolumn{2}{|c|}{ Arrival time } & \multicolumn{2}{|c|}{ Arrival Rate } & \multicolumn{2}{|c|}{ Service Time } & \multicolumn{2}{|c|}{ Service Rate } \\
\hline Monday & 1.38 & 0.98 & 1.56 & 38.46 & 61.22 & 2.33 & 3.86 & 15.54 & 24.69 \\
\hline Tuesday & 1.29 & 1.14 & 1.82 & 32.96 & 52.47 & 2.19 & 3.48 & 17.21 & 27.34 \\
\hline Wednesday & 0.92 & 1.20 & 1.65 & 36.14 & 50.00 & 2.22 & 3.07 & 19.51 & 26.97 \\
\hline Thursday & 1.15 & 1.25 & 1.93 & 31.14 & 47.86 & 2.11 & 3.24 & 18.47 & 28.41 \\
\hline Friday & 1.02 & 1.34 & 1.96 & 30.55 & 44.90 & 2.14 & 3.15 & 19.02 & 28.00 \\
\hline
\end{tabular}

The confidence intervals show the range of number of customers that arrive within an hour time frame for each day and the range of number of customers served.

\section{1. $\quad$ Test for Poisson distribution}

This test is statistically tested to show the pattern in which the customers arrive at the system. The test was carried out for both peak and off-peak periods. Peak periods were between 10:00hrs -11 :00hrs and 14:00hrs -15 :00hrs.

The following data from Monday to Friday has been compiled to obtain Table 2 below:

Table 2: Relative Frequency and probabilities for peak period

\begin{tabular}{|l|l|l|l|l|}
\hline Arrivals & Frequency & $f_{x}$ & Relative frequency & $p_{r}[R=r]$ \\
\hline 0 & 0 & 0 & 0 & 0.0004 \\
\hline 1 & 20 & 20 & 0.081 & 0.0459 \\
\hline 2 & 21 & 42 & 0.085 & 0.0668 \\
\hline 3 & 21 & 63 & 0.085 & 0.092 \\
\hline 4 & 24 & 96 & 0.096 & 0.094 \\
\hline 5 & 24 & 120 & 0.096 & 0.102 \\
\hline 6 & 25 & 150 & 0.101 & 0.156 \\
\hline 7 & 25 & 175 & 0.101 & 0.132 \\
\hline 8 & 26 & 208 & 0.105 & 0.127 \\
\hline 9 & 31 & 279 & 0.125 & 0.113 \\
\hline 10 & 31 & 310 & 0.125 & 0.110 \\
\hline & $\Sigma=\mathbf{2 4 8}$ & $\sum=\mathbf{1 4 6 3}$ & & \\
\hline
\end{tabular}

$\frac{\sum f x}{\sum f i}=\frac{1463}{248}=5.899$

Take $\mu=\lambda t_{\text {in }} 1$ hour 
INDEPENDENT JOURNAL OF MANAGEMENT \& PRODUCTION (IJM\&P)

http://www.ijmp.jor.br

v. 8, n. 2, April - June 2017

ISSN: 2236-269X

DOI: 10.14807/ijmp.v8i2.576

$\lambda=\frac{\lambda t}{t}=\frac{5.899}{60}=0.098 \mathrm{cpm}$

\section{Peak period}

0,2

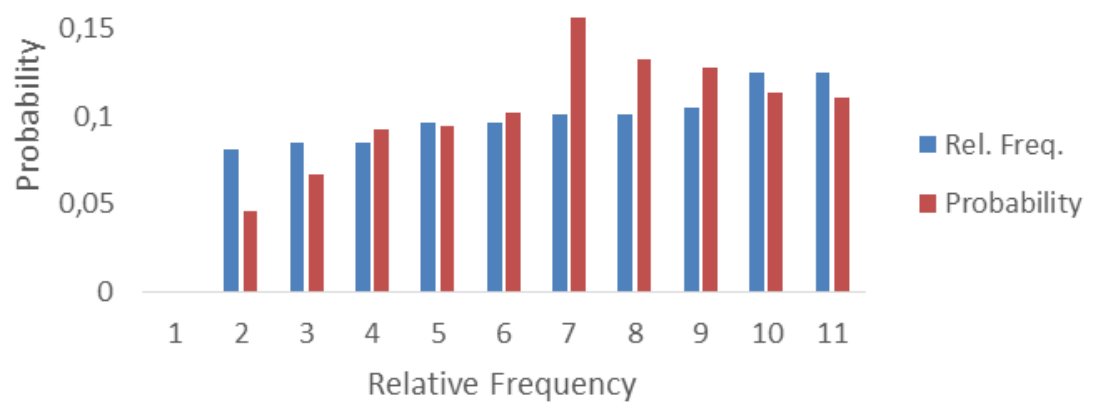

Figure 1: Compares of Relative Frequency to Probabilities for peak period

Table 3: Relative Frequency and probabilities for off peak period

\begin{tabular}{|l|l|l|l|l|}
\hline Arrivals & frequency & $f x$ & Relative frequency & $p_{r}[R=r]$ \\
\hline 0 & 0 & 0 & 0 & 0.000005 \\
\hline 1 & 11 & 11 & 0.030 & 0.060 \\
\hline 2 & 11 & 22 & 0.030 & 0.040 \\
\hline 3 & 13 & 39 & 0.036 & 0.015 \\
\hline 4 & 13 & 52 & 0.036 & 0.045 \\
\hline 5 & 14 & 70 & 0.039 & 0.0211 \\
\hline 6 & 15 & 90 & 0.041 & 0.0326 \\
\hline 7 & 15 & 105 & 0.041 & 0.0396 \\
\hline 8 & 15 & 120 & 0.041 & 0.0505 \\
\hline 9 & 16 & 144 & 0.044 & 0.0423 \\
\hline 10 & 16 & 160 & 0.044 & 0.0406 \\
\hline 11 & 17 & 187 & 0.047 & 0.0449 \\
\hline 12 & 17 & 204 & 0.047 & 0.0459 \\
\hline 13 & 19 & 247 & 0.052 & 0.0490 \\
\hline 14 & 19 & 266 & 0.052 & 0.0538 \\
\hline 15 & 19 & 285 & 0.052 & 0.0565 \\
\hline 16 & 19 & 304 & 0.052 & 0.0585 \\
\hline 17 & 24 & 408 & 0.066 & 0.0621 \\
\hline 18 & 24 & 432 & 0.066 & 0.070 \\
\hline 19 & 25 & 475 & 0.069 & 0.074 \\
\hline 20 & 41 & 820 & 0.113 & 0.122 \\
\hline & $\Sigma=\mathbf{3 6 3}$ & $\Sigma=\mathbf{4 4 4 1}$ & & \\
\hline
\end{tabular}

$\frac{\sum f x}{\sum f i}=\frac{4441}{363}=12.234$

if $\mu=\lambda t=12.234$

then $\lambda=\frac{12.234}{60}=0.20 \mathrm{cpm}$

but $p_{r}[R=r]=\frac{\lambda t^{r} \cdot \square^{-\lambda t}}{r !}$ 


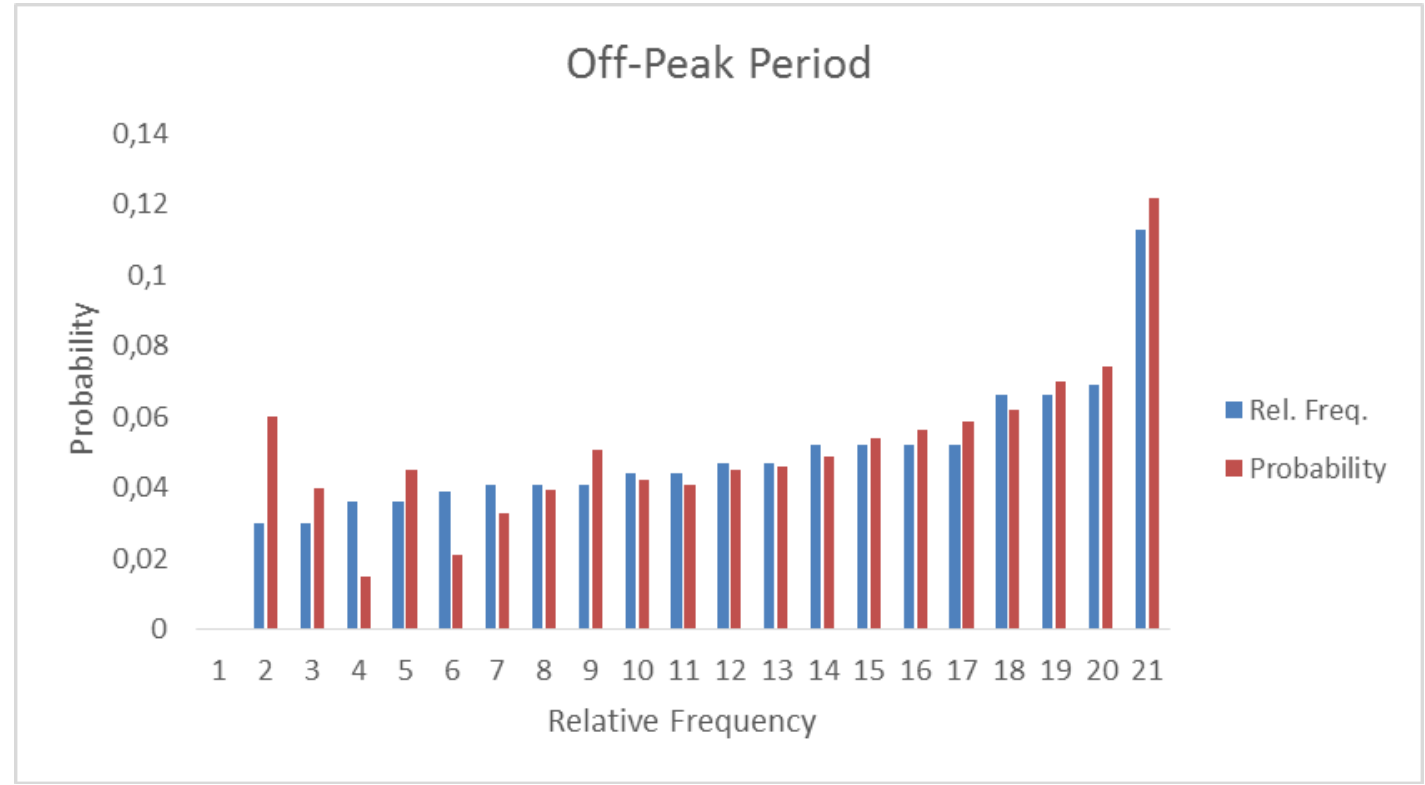

Figure 2: Compares of Relative Frequency to Probabilities

\subsection{Chi Square Goodness of Fit test for peak period}

Using Chi Square goodness of fit to test, the data for both peak and off peak periods, it is shown that the observed frequency and theoretical frequency obtained are $f_{0}=\sum 248$ and $f_{e}=n^{*} p(x)=\sum 257.696$

This gives us a chi square $\chi^{2}$ value of $\sum 289.193$

With a degree of freedom:

$$
\begin{aligned}
n-1 & =11-1 \\
& =10
\end{aligned}
$$

Where $\mathrm{n}=11$

and a 0.05 level of significance from tables, the critical value of $\chi^{2}$ with 10 degree of freedom is given as 18.31

\subsection{Hypothesis/Decision rule:}

Reject $\mathrm{H}_{\mathrm{o}}$ : if $\chi^{2}<18.31$ otherwise do not reject $\mathrm{H}_{\mathrm{o}}$ $\chi^{2}=289.193>18.31$

Therefore, $\mathrm{H}_{\mathrm{o}}$ is not rejected 
DOI: 10.14807/ijmp.v8i2.576

\subsection{Chi Square Goodness of Fit test for off-peak period}

Observed frequency and theoretical frequency obtained are $f_{0}=\sum 363$ and $f_{e}=n^{*} p(x)=\sum 357.899$

This gives us a chi square $\chi^{2}$ value of $\sum 7347.49$

Degree of freedom:

$\mathrm{n}-1=21-1$

$$
=20
$$

Using 0.05 level of significance, from tables, the critical value of $\chi^{2}$ with 20 degree of freedom is 31.41

Reject $H_{O}:$ if $\chi^{2}<31.41 \quad$ otherwise do not reject $H_{O}$

$$
\chi^{2}=7347.49>31.41
$$

Therefore $H_{O}$ is not rejected

\subsection{Test for exponential distribution}

The data obtained is also tested to show the pattern in which the service rate follow. The test was carried out for both peak and off-peak periods.

Table 4: Daily count for service rate

\begin{tabular}{|l|l|l|l|l|l|l|}
\hline Days/time & $\mathbf{9 - 1 0}$ & $\mathbf{1 0} \mathbf{- 1 1}$ & $\mathbf{1 1 - 1 2}$ & $\mathbf{1 2} \mathbf{- 1}$ & $\mathbf{1 - 2}$ & $\mathbf{2 - 3}$ \\
\hline Monday & 6.0769 & 4.7 & 2.647 & 4.317 & 4.125 & 5.08 \\
\hline Tuesday & 6 & 5 & 2.882 & 3.875 & 3 & 3.885 \\
\hline Wednesday & 6.818 & 3.333 & 2.857 & 3.875 & 3 & 3.885 \\
\hline Thursday & 5.273 & 3.367 & 2.857 & 3.056 & 3.187 & 2.583 \\
\hline Friday & 5.538 & 4.4 & 2.833 & 3.111 & 3.063 & 2.667 \\
\hline
\end{tabular}

Table 5: Exponential distribution for peak period

\begin{tabular}{|l|l|}
\hline Service rate $(\mu)$ & Expected value $E(T)$ \\
\hline 2.583 & 0.38714 \\
\hline 2.667 & 0.37495 \\
\hline 3.333 & 0.30003 \\
\hline 3.367 & 0.29700 \\
\hline 3.885 & 0.25740 \\
\hline 3.885 & 0.25740 \\
\hline 4.400 & 0.22727 \\
\hline 4.700 & 0.21276 \\
\hline 5.000 & 0.20000 \\
\hline 5.080 & 0.19685 \\
\hline
\end{tabular}


ISSN: 2236-269X

DOI: 10.14807/ijmp.v8i2.576

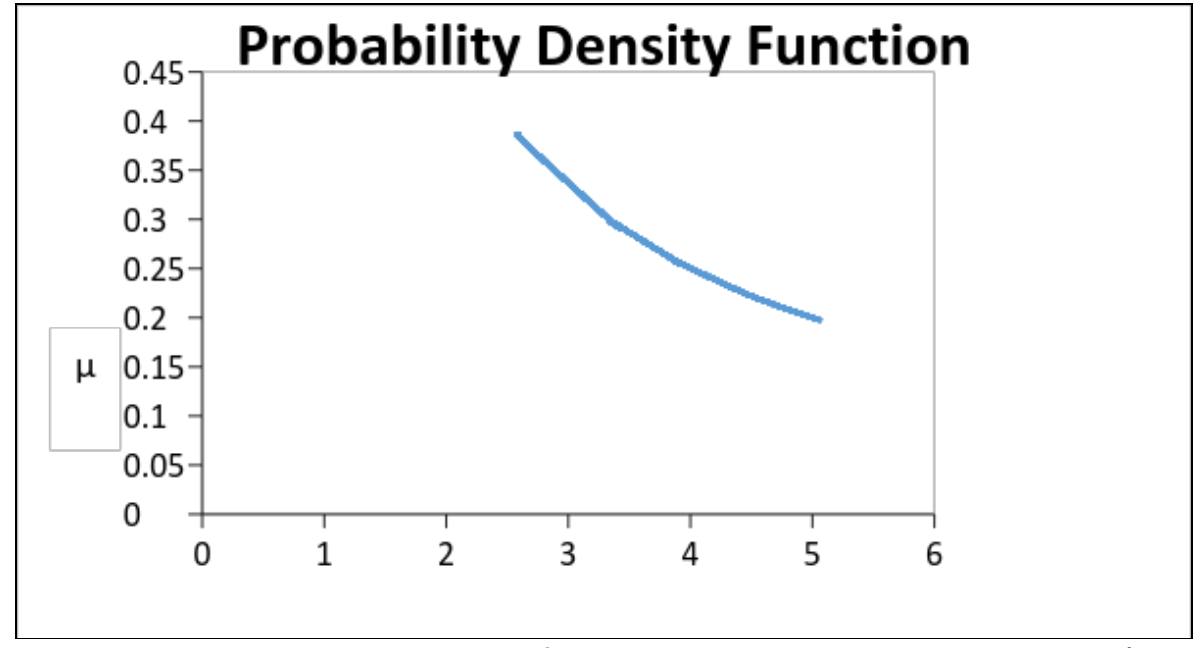

Figure 3: Probability Density Function for the exponential distribution. (Peak Period)

Table 6: Exponential distribution for off Peak Period

\begin{tabular}{|l|l|}
\hline Service rate $(\mu)$ & Expected value $\mathrm{E}(\mathrm{T})$ \\
\hline 2.647 & 0.3777 \\
\hline 2.833 & 0.3529 \\
\hline 2.857 & 0.3500 \\
\hline 2.857 & 0.3500 \\
\hline 2.882 & 0.3469 \\
\hline 3.000 & 0.3333 \\
\hline 3.000 & 0.3333 \\
\hline 3.056 & 0.3272 \\
\hline 3.063 & 0.3264 \\
\hline 3.111 & 0.3214 \\
\hline 3.187 & 0.3137 \\
\hline 3.875 & 0.2580 \\
\hline 3.875 & 0.2580 \\
\hline 4.125 & 0.2424 \\
\hline 4.317 & 0.2316 \\
\hline 5.273 & 0.1896 \\
\hline 5.538 & 0.1805 \\
\hline 6.000 & 0.1666 \\
\hline 6.077 & 0.1645 \\
\hline 6.818 & 0.1466 \\
\hline
\end{tabular}

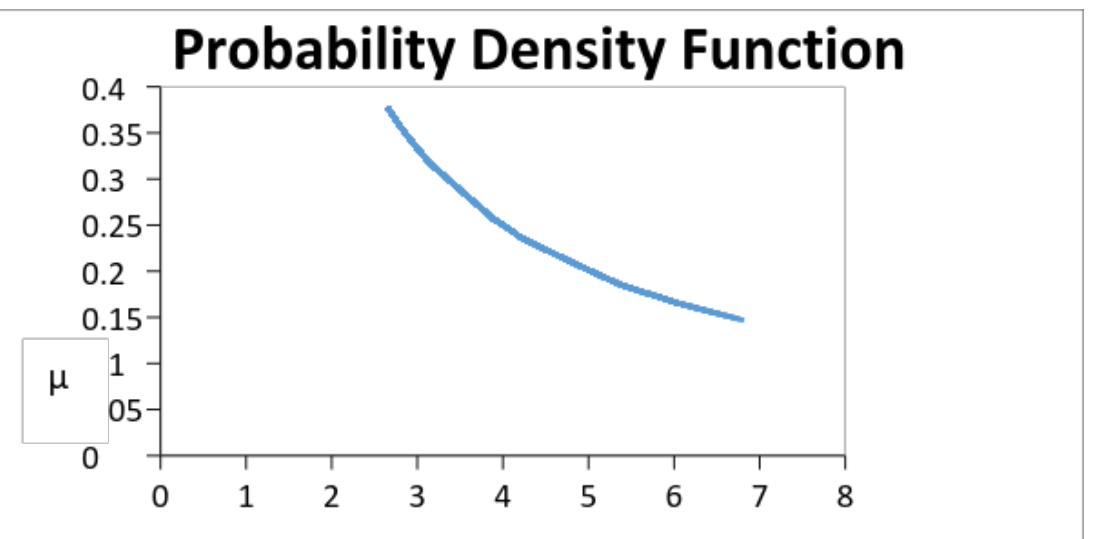

Figure 4: Probability Density Function for the exponential distribution. (Off Peak Period) 
The various mean for Monday to Friday of the data collected have been obtained using formula:

Arrival rate $=\frac{\text { Nunber of Customers }}{\text { Duration of data collection }}$

Service rate $=\frac{\text { Average Service Rate }}{\text { Number of Customers }}$

Duration of data collection $=180$ minutes

Table 7: Arrival and Service rate for Monday - Friday

\begin{tabular}{|l|l|l|}
\hline Days & Arrival Rate & Service Rate \\
\hline Monday & 47.0 & 19.0 \\
\hline Tuesday & 40.6 & 21.13 \\
\hline Wednesday & 42.0 & 22.64 \\
\hline Thursday & 37.6 & 22.38 \\
\hline Friday & 36.0 & 22.64 \\
\hline
\end{tabular}

Therefore, Mean arrival rate $=40$ Customers per hour

Mean service rate $=22$ Customers per hour

The average number of customers waiting in line $=17.9$ Customers

Average time spent waiting in line $=0.45$ hours

Expected waiting time for a customer in the system $=0.49$ hours

Expected number of customers in the system $=19.72$ Customers

\section{DISCUSSIONS}

The following results and test obtained are discussed in detail. The confidence interval for both arrival and service time at $95 \%$ shows the range of number of customers that come into the system and also the range of customers served on a daily basis. It also shows that there are still some customers not being served and are waiting for their turn in the queue to be served. This is however due to the service provided by a server to a customer.

For testing the data to show that it fits the Poisson distribution, Tables $2 \& 3$ shows values of the relative frequency to that of the probabilities for the peak period. However, the plot in figure 4.2 shows a close relationship between the probabilities and the relative frequencies. A goodness of fit test is also calculated using chi square to show that the data obtained follows a Poisson distribution. The theoretical 
INDEPENDENT JOURNAL OF MANAGEMENT \& PRODUCTION (IJM\&P)

http://www.ijmp.jor.br

v. 8, n. 2, April - June 2017

ISSN: 2236-269X

DOI: 10.14807/ijmp.v8i2.576

frequency is compared to the actual frequency obtained. A 0.05 level of significance is used. The same procedure was also carried out for off-peak period to show that the data (arrival rate) follows a Poisson distribution.

The plot in Figures 4.4 and 4.5 show the pattern in which the service rate follows. From the plot, it shows that the random variable with parameter $\mu$ is exponentially distributed. The random variable $\mu$ is plotted against the expected value.

However, from the calculations of the queuing parameters, it is shown that the performance of the servers on average was sufficiently good. It can be seen that the probability of the servers to be busy was 0.909 which was $90.9 \%$. The average number of customers waiting in a queue is $L_{q}=17.9$ customers per 2-servers. The waiting time in a queue per server is $W_{q}=0.45$ hours which are normal time in a busy server. The plot in Figure 4.6 shows the probability curve which takes the shape of the Probability Density Function.

This is a clear indication that the data obtained follows an exponential distribution. Also, the utilization obtained was directly proportional to the mean number of customers. This simply means that the mean number of customers will increase as the utilization increases. The utilization rate at the restaurant was highly above average at 0.909 . This was the utilization rate during breakfast and lunch time at week days. When the service rate was higher, the utilization will be lower which reduces the probability of the customers going away.

\section{CONCLUSION}

Providing insight into the study of queue theory through the examination of the Blue Meadows Waiting Line Model, our work presents a foundation for the development of strategies that may enhance customer satisfaction in fast food restaurants and other service industries. We evaluated the performance of single channels, two servers in Blue-Meadows restaurant at the University of Benin. The utilization rate at the restaurant was highly above average at 0.909 .

This gave the probability of the servers to be busy at $90.9 \%$. The Model played a key role in highlighting the operations effectiveness of the services rendered as well as identifying need for improvements. In order to improve operations within the waiting line, the service rate should be improved. This research 
INDEPENDENT JOURNAL OF MANAGEMENT \& PRODUCTION (IJM\&P)

http://www.ijmp.jor.br

v. 8 , n. 2, April - June 2017

ISSN: 2236-269X

DOI: 10.14807/ijmp.v8i2.576

can help improve the quality service at Blue Meadows restaurant. The result of the research work may serve as a reference to analyze the current system and improve the next system.

However, the restaurant can now estimate how many customers will wait in the queue and how many will walk away each day. By anticipating the number of customers coming and going in a day, the restaurant can set a target profit that should be achieved daily depending on the purchases each customer makes. Some of the limitations of the study included: the inaccuracy of results since some of the data that were used were based on approximation. It is hoped that findings from this study can contribute to the betterment of Blue-Meadows restaurant in terms of its way of dealing with customers.

\section{REFERENCES}

ANDREWS, B.; PARSONS, H. (1993) Establishing telephone-agent staffing levels through economic optimization. Interfaces, v. 23, p. 14-20.

AUTY, S. (1992) Consumer choice and segmentation in the restaurant industry. The Service Industries Journal, v. 12, n. 3, p. 324-339.

BRANN, D. M.; KULICK, B. C. (2002) Simulation of restaurant operations using the Restaurant Modeling Studio. In: WINTER SIMULATION CONFERENCE, proceedings... IEEE Press, December, 2002, p. 1448-1453.

CHOWDHURRY, M. S. R. (2013) Queuing theory model used to solve the waiting line of a bank - a study on Islami Bank Bangladesh Limited, Chawkbazar Branch, Chittagong. Asian Journal of Social Sciences and Humanities, v. 2, n. 3, p. 468478.

COOPER, R. B. (1990) "Queueing Theory". In HEYMAN, D. P.; SOBEL, M. J. (Ed.) Stochastic Models, Amsterdam: North-Holland (Elsevier), p. 469-518.

COPE, R. F.; COPE III, R. F.; BASS, A. N.; SYRDAL, H. A. (2011) Innovative knowledge management at Disney: human capital and queuing solutions for services. Journal of Service Science, v. 4, n. 1, p. 1-20.

CURIN, S. A.; VOSKO, J. S.; CHAN, E. W.; TSIMHONI, O. (2005) Reducing service time at a busy fast food restaurant on campus. In: WINTER SIMULATION CONFERENCE, proceedings... IEEE Press, December, 2005.

DHARMAWIRYA, M.; ADI, E. (2011) Case study for restaurant queuing model. In: International Conference On Management And Artificial Intelligence, IPEDR, Bali: IACSIT Press, n. 6, p. 52-55.

JONES, P.; DENT, M. (1994) Improving service: Managing response time in hospitality operations. International Journal of Operation and Production Management, v. 14, p. 52-8.

KAVITHA, J.; PALANIAMMAL, S. (2014) Efficient path selection and data transmission using queue in open shortest path first. International Journal of 
Computer Science and Application, v. 3, n. 4, p. 139-144. Available: http://www.ij-csa.org. Access: 4th November, 2016. DOI: 10.14355/ijcsa.2014.0304.01.

KENDALLI, D. G. (1953) Stochastic processes occurring in the theory of queues and their analysis by the method of the Imbedded Markov Chain. The Annals of Mathematical Statistics. v. 24, n. 3, p. 338-354. DOI: 10.1214/aoms/1177728975.

NOSEK, R. A.; WILSON, J. P. (2001). Queuing theory and customer satisfaction: a review of terminology, trends, and applications to pharmacy practice. Hospital Pharmacy, v. 36, n. 3, p. 275-279.

KHARWAT, A. K. (1991). Computer simulation: an important tool in the fast-food industry. In: Winter Simulation Conference, proceedings... IEEE Press, p. 811-815.

LI, L.; LEE, Y. S. (1994). Pricing and delivery-time performance in a competitive environment. Management Science, v. 40, n. 5, p. 633-646.

MANDIA, S., (2009) Design of Queuing System, Department of Mechanical and Industrial Engineering.

OLADEJO, M. O.; AGASHUA, N. U.; TAMBER, J. A. (2015) Optimizing the queuing system of a fast food restaurant: a case study of Ostrich Bakery. International Journal of Development in Engineering and Technology, v. 4, n. 8, p. 7-15.

PIERCE (II), R. A.; ROGERS E. M.; SHARP, M. H. (1990) Outpatient pharmacy redesign to improve workflow, waiting time, and patient satisfaction. American Journal of Hospital Pharmacy, v. 47, p. 351-6.

PROCTOR, R. A. (1994). Queues and the power of simulation: helping with business decisions and problems. Management Decisions, v. 32, p. 50-5.

RAMAKRISHNA, R.; MOHAMEDHUSIEN, K. (2015) Simulation technique for queuing theory: a case study. International Journal of Research and Applications, v. 2, n. 8, p. 388-396.

ROSENFELD, M. (1997). Arlington DMV's speedy service: new system eliminates long lines. The Washington Post, August 8:A1, A17

SHARMA, J. K. (2010) Operations Research: Theory and Applications 4. ed. New Delhi: MacMillan Publishers.

SOMANI, S. M.; DANIELS, C. E.; JERMSTAD, R. L. (1982) Patient satisfaction with outpatient pharmacy services. American Journal of Hospital Pharmacy, v. 39, p. 1025-7.

SZTRIK, J. (2010) Queueing theory and its applications: a personal view. In: The 8th International Conference On Applied Informatics, proceedings... Eger Hungary, January 27 - 30, v. 1, p. 9-30.

TYAGI, A.; SAROA, M. S.; SINGH, T. P. (2014) Application of Stochastic Queue Model in a Restaurant $-A$ case Study. Aryabhatta Journal of Mathematics and Informatics, v. 6, n. 1, p. 115-118.

YAKUBU, A. N.; NAJIM, U. (2014) An application of queuing theory to ATM service optimization: a case study. Mathematical Theory and Modeling, v. 4, n. 6, p. 1123. 
ISSN: 2236-269X

DOI: 10.14807/ijmp.v8i2.576

ZHANG, L. J.; NG, W. W. J. L.; TAY, S. C. (2000) Discrete-event simulation of queuing systems. The Sixth Youth Science Conference, Ministry of Education, Singapore, p. 1-2. 